\title{
Práticas Educativas na Escola Dialogando com os Estudantes
}

\author{
Carina Alexandra Rondini ${ }^{1}$ \\ Bianca Molica Marinheiro²
}

\begin{abstract}
Resumo
Trata-se de uma pesquisa de enriquecimento de material pedagógico, derivado do processo de escuta de estudantes do 4o ano do Ensino Fundamental, com vistas a proporcionar a construção de um ambiente diferenciado em sala de aula, mediante práticas pedagógicas dinamizadoras. Por meio da pesquisa-ação objetivou-se escutar os estudantes e incorporar essas informações ao material pedagógico adotado pela escola, buscando meios de dinamizá-lo. Os relatos evidenciam que, ao se tratar de educação, uma contribuição nova e original não necessariamente deriva de práticas mirabolantes e caras. Como ruptura epistemológica, os estudantes percebem-se ou não coparticipantes da elaboração do processo de ensino-aprendizagem e passam a ver as ações realizadas como algo prazeroso.
\end{abstract}

Palavras-chave: Práticas pedagógicas. Material pedagógico. Escuta de estudantes. Práticas pedagógicas.

\section{DYNAMIC STRATEGIES IN SCHOOL: \\ Talking With Students}

\begin{abstract}
It is an account of teaching materials enriching experience, derived from the process of listening to students in the fourth grade of elementary school, in order to provide for the construction of a unique environment in the classroom by a dynamic pedagogical practices. Through action research, collaborative, is aimed to listen to the students and incorporate that
\end{abstract}

${ }^{1}$ Universidade Estadual Paulista (Unesp), Instituto de Biociências, Letras e Ciências Exatas, Campus de São José do Rio Preto. Departamento de Ciência de Computação e Estatística. carina@sjrp.unesp.br

2 Universidade Estadual Paulista (Unesp), Faculdade de Ciências e Letras, Campus de Assis. bianca.mm@uol.com.br

\begin{tabular}{l|l|l|l|l}
\hline Editora Unijuí & Ano 32 & $n^{\circ} 101$ & Jan./Abr. 2017 & P. 81-104
\end{tabular}


information when learning materials adopted by the school, looking for ways to make it more dynamic. The reports show that when it comes to education, a new and original contribution, not necessarily derived from fancy and expensive practices. As an epistemological rupture, students realize it or not partakers of the development of the teaching-learning process, and begin to see the actions taken as something pleasant.

Keywords: Dynamic pedagogical practices. Enrichment of pedagogical material. Listening students. 
Entre as transformações vividas no século 20, uma delas foi a democratização do saber - o que antes era restrito a um seleto grupo de pessoas e sinônimo de poder na sociedade é, agora, dirigido também às classes populares. A ciência moderna, contudo, torna a educação voltada para a tecnologia, originando o cenário do século 21: a "sociedade da informação", do conhecimento gerado e transformado em tempo real (MOSÉ, 2013). Num mundo no qual a informação é agilmente disseminada e de fácil acesso, ensinar - na escola - precisa ser mais do que difundir um conjunto de informações para que os estudantes o assimilem. É necessário auxiliar o educando no e para o processo de ensino-aprendizagem, ajudá-lo a estabelecer relações entre o que aprendeu e contextualizar esse assunto/tema em sua vida, construindo, assim, o conhecimento (ANTUNES, 2013). Salienta Mosé (2013):

Ensinar não pode ser [essencialmente] transmitir conhecimentos, mas, antes de tudo, provocar interesses e dúvidas, fazer com que brotem questões e desenvolver métodos de pesquisa, de filtragem e seleção de dados, de ordenação de conteúdos, de construção da argumentação. Só há conhecimento quando há interpretação. O contrário não é aprendizado (p. 13, grifos nossos).

Para pensar uma educação em que o professor auxilie seus estudantes e os ajude nessa construção do saber é preciso pressupor o diálogo. "Devemos reconhecer que as crianças são participantes ativos de sua própria aprendizagem" e, portanto, sujeitos ativos na relação ensino-aprendizagem (KINNEY; WHARTON, 2009, p. 23). Ademais, se esse processo envolve o debate entre as informações adquiridas e a realidade objetiva desse estudante, torna-se necessário conhecer seu contexto histórico, econômico e social - ou, em outras palavras, o seu "mundo" (ANTUNES, 2013). Dessa forma, o diálogo entre o professor e o estudante é imprescindível, como exposto por Freire (2015):

[...] ensinar não é transferir conhecimentos, conteúdos, nem formar é ação pela qual um sujeito criador dá forma, estilo ou alma a um corpo indeciso e acomodado. Não há docência sem discência, as duas se explicam e seus sujeitos, apesar das diferenças que os conotam, não se reduzem à condição de objeto um do outro. Quem ensina aprende ao ensinar e quem aprende ensina ao aprender (p. 25, grifo do autor). 
Sendo assim, o educador que aspira a contribuir para o pleno desenvolvimento do potencial de seus educandos precisa, mediante uma metodologia diferenciada e dinâmica, incentivar a capacidade crítica, a curiosidade e a insubmissão desses estudantes (FREIRE, 2015).

"Se as crianças não receberem a chance de se tornarem curiosas e de descobrir respostas para suas perguntas, elas não se verão como aprendizes de sucesso, ou não considerarão a escola um lugar em que podem aprender algo interessante ou relevante" (HELM, 2005, p. 14). Tendo em vista esse cenário, é inevitável pensar em práticas pedagógicas diferenciadas, de forma a responder às necessidades dos educandos e, consequentemente, àquilo que a sociedade contemporânea exige deles.

Em vista disso, com base em um trabalho colaborativo de pesquisa-ação entre as partes envolvidas - escola pública de ensino e a universidade - objetivou-se dinamizar o fazer pedagógico, enriquecendo o material didático adotado pela escola, com vistas ao desenvolvimento e engajamento dos estudantes, por meio do favorecimento da sua escuta e protagonismo. O que pode ser visto como

uma tarefa um tanto ambígua, pois se, de um lado, [o professor] tem a função de estabelecer os limites da realidade, das obrigações e das normas, de outro, ele desencadeia novos dispositivos para que o aluno se diferencie, tenha autonomia sobre o seu próprio aprendizado e sobre sua própria vida (MATTEI, 2008, p. 82).

Dessa forma, o professor pode se equivocar em achar que dar mais tempo, deixar o estudante "livre", pode, por si só, desencadear o seu desenvolvimento. Ao contrário, e, além disso, é necessário que o professor se aproprie de seu papel de instigador para desencadear este processo.

Trata-se de um recorte de um projeto de pesquisa ${ }^{3}$ formulado no ano letivo de 2014. O projeto foi realizado com uma turma de $4^{\circ}$ ano do Ensino Fundamental - Ciclo I - de uma escola estadual do interior do Estado de São

\footnotetext{
Projeto de Iniciação Científica intitulado "Ensino Diferenciado: Atendendo o potencial dos educandos". Agência de Fomento: Fundação de Amparo à Pesquisa do Estado de São Paulo Fapesp (Processo $n^{\circ}$ 2013/12953-2). O projeto foi aprovado pelo Comitê de Ética e Pesquisa da Faculdade de Ciências e Letras - FCL - Unesp/Assis. CAAE: 15643113.5.0000.5401. Número do Parecer: 660.465. Data da Relatoria: 5/5/2014.
} 
Paulo. A turma é composta por 23 estudantes, dos quais 13 são meninas. Para seu desenvolvimento foi empreendida a metodologia da pesquisa-ação. Sobre esse tipo de investigação, Thiollent (2008, p. 11) destaca:

Os temas e problemas metodológicos apresentados na pesquisa-ação são limitados ao contexto da pesquisa com base empírica, isto é, da pesquisa voltada para a descrição de situações concretas e para a intervenção ou a ação orientada em função da resolução de problemas efetivamente detectados nas coletividades consideradas.

Ainda segundo o autor, essa metodologia permite aos pesquisadores desempenhar papel ativo diante dos problemas encontrados, "no acompanhamento e na avaliação das ações desencadeadas em função dos problemas" (Ibidem, p.18). Acrescenta que a pesquisa-ação exige uma forma de relação participativa/ colaborativa entre os pesquisadores e os sujeitos da pesquisa. Essa metodologia em muito convém ao contexto educacional, se utilizada como um instrumento de transformação de conhecimento, buscando habilitar o professor a elaborar e praticar estratégias dinâmicas que possam contribuir com sua metodologia de ensino. Dessa maneira, considera-se necessário um trabalho conjunto, colaborativo, envolvendo a parceria para promover mudanças no ambiente escolar (MENDES; VILARONGA; ZERBATO, 2014).

Tendo ainda em vista o exposto por Kinney e Wharton (2009), para realizar mudanças metodológicas na prática pedagógica é preciso considerar também os pensamentos e interesses dos estudantes, uma vez que são sujeitos ativos do processo de ensino-aprendizagem e devem, portanto, estar no centro dele.

Dessa forma, todo o processo de ação-reflexão-ação, empreendido no presente trabalho, foi adaptado a partir da Metodologia da Mediação Dialética (MMD), cujos "momentos pedagógicos" de vivência - resgatando os conhecimentos iniciais dos estudantes; problematizando; sistematizando e produzindo expressão da síntese, dirigidos aos estudantes, descritos por Oliveira, Almeida e Arnoni (2007, p. 148-149), "potencializa-lhes a superação das representações imediatas no conceito científico, mediato". 
Considerando que para Oliveira, Almeida e Arnoni “resgatar é buscar um mesmo ponto de partida para o processo de ensino, provisoriamente comum ao professor e ao aluno" (2007, p. 148), nossa primeira ação constituiu-se em uma Roda de Conversa, orientada por uma entrevista semiestruturada, com duração aproximada de $1 \mathrm{~h} 30 \mathrm{~min}$, na presença da professora regente. Nessa prática foi perguntado aos educandos sobre o que mais e menos gostavam na escola, o que pensavam sobre a sala de aula - incluindo aulas, espaço físico e disposição das carteiras -, o que gostavam e o que gostariam de fazer na escola, se gostavam das atividades propostas pela professora, o que gostavam de fazer em casa, quais temas lhes interessaria pesquisar, quais atividades lhes interessaria mais, entre outras questões.

Entre os apontamentos trazidos pelos estudantes podemos destacar: realizar leitura de poemas para os amigos; realizar leitura compartilhada, em voz alta, desde que o colega leia bem; fazer uma biografia de um autor; efetuar pesquisas e apresentá-las aos colegas; as salas não vedam o barulho externo, atrapalhando a concentração/aproveitamento da aula. Os estudantes demonstraram igualmente uma relação positiva com o material usado pela escola, visto que declararam gostar "das atividades do Ler" - o Ler e Escrever (SÃO PAULO, 2010) -, além de gostarem de "aprender sobre o meio ambiente" e terem interesse em atividades lúdicas em geral.

Com relação à sala de aula, os estudantes afirmaram gostar de trabalhar em duplas ou grupos, mas que algumas atividades precisam ser feitas em fileira. Apontaram problemas de estrutura - como "o ventilador faz barulho", "a sala é muito pequena" e "vem barulho da quadra e da rua". Ademais, demonstraram interesse em sair da sala de aula e em participar de excursões.

Quando perguntados sobre o que gostariam de fazer na escola, relataram usar o computador, fazer um piquenique e ir à praça próxima da escola. Quanto às atividades propostas pela professora e possíveis mudanças, dividiram-se entre gostar ou não, apontaram haver dificuldades e que a educadora os auxiliava, quando havia dúvidas, mas concluíram que "já está bom assim". 
Para Oliveira, Almeida e Arnoni, "Esse saber inicial do aluno (ponto de partida) constitui material para o problematizando ['colocar o sujeito em uma situação de ensino problematizadora, capaz de levá-lo a compreender mentalmente entre seu saber imediato e o saber mediato (p. 151)']" (2007, p. 153). Por conseguinte, a partir desses apontamentos buscamos elaborar, em colaboração com a professora regente e a coordenadora pedagógica, práticas diferenciadas que dinamizassem a sala de aula. Para tanto buscamos auxílio na literatura (GUENTHER, 2012; ANTUNES, 2013; KINNEY; WHARTON, 2009; SANTOS, 2011) e optamos por adotar o material pedagógico exigido pela escola, uma vez que os estudantes não apresentaram críticas a ele e, pelo contrário, apreciavam as atividades ali propostas. Para o presente trabalho vamos refletir acerca de quatro práticas, explanadas a seguir.

\section{Descrição das atividades}

\section{Prática 1 - Diário de Bordo}

De acordo com Kinney e Wharton, documentar sistematicamente o que as crianças fazem e trazem para a sala pode tornar "[...] visível a aprendizagem das crianças e as encoraja a se tornarem o centro da sua própria aprendizagem" (p. 27). Procurando fazer esse registro, propusemos o "Diário de Bordo", apoiando-nos no sugerido por Guenther (2012), que consiste em entregar periodicamente aos estudantes um pequeno bloco de folhas e encorajá-los a registrar suas ideias de forma livre, sobre temas diversos - a sala de aula, a escola, a família, a comunidade, entre outros. Conforme opção da professora regente, no entanto, os diários foram utilizados exclusivamente para registro em sala, não sendo possível entregá-los periodicamente para registro livre em casa.

Em vista disso, os diários foram usados para o registro das demais práticas realizadas e da opinião dos estudantes acerca destas. A ideia de documentar seus apontamentos nos diários era, também, possibilitar aos estudantes uma avaliação de sua aprendizagem e da relação deles com as práticas diversificadas, e às professoras e pesquisadoras, a avaliação das intervenções, considerando o olhar 
dos educandos. Buscamos avaliar as práticas de forma mais abrangente, tendo em conta também o apontado pelos estudantes para a elaboração de práticas condizentes com sua realidade e necessidades - como sugerido por Kinney e Wharton (2009).

Os Diários de Bordo foram apresentados aos alunos, pela primeira vez, no dia 11 de junho de 2014, e permaneceram guardados na escola durante o andamento do projeto, sendo entregues aos estudantes após a realização de alguma prática referente à pesquisa, a fim de realizarem o registro - feito sempre em sala de aula. Os cadernos só foram recolhidos para análise durante o recesso de julho e ao término do ano letivo, em dezembro de 2014.

Os registros dos diários estarão presentes durante a exposição das demais práticas.

\section{Prática 2 - Enriquecimento do Projeto Meios de Comunicação}

Presente no material do Ler e Escrever (SÃO PAULO, 2010, p. 91), o Projeto Didático "Meios de Comunicação" é apresentado da seguinte maneira:

O projeto Meios de Comunicação tem por finalidade contribuir para a construção de capacidades e procedimentos de leitura e escrita envolvidos na ação de estudar. Essas capacidades e procedimentos são imprescindíveis para a construção da autonomia, tão necessária ao estudante ao longo de sua vida escolar e para além dela. Além desse objetivo, mais geral, os alunos deverão, ao final do projeto, expor aos colegas o resultado de sua pesquisa, mostrando os conhecimentos adquiridos sobre os principais meios de comunicação existentes atualmente.

No Guia de Planejamento e Orientações Didáticas, o projeto contempla, em sua organização geral, as seguintes etapas: 1 - Apresentação do Projeto; 2 - Ler para estudar; 3 - Escolha dos meios de comunicação a serem pesquisados; 4 - Lendo para aprender mais sobre; 5 -Ampliar os conhecimentos sobre 
esquema e sua relação com as situações de exposição oral, que envolve os estudos de esquema, seminário e organização da apresentação; 6 - Apresentação e Avaliação, que inclui o ensaio de seminário, sua apresentação e a avaliação.

Trabalhamos da seguinte forma: à primeira etapa do projeto foi dado o subtítulo "Minha vida sem os meios de comunicação do século 21". Iniciou-se em sala uma discussão sobre o que eram "Meios de Comunicação", sendo sugeridos pelos estudantes Facebook, WhatsApp, Twitter e celular. Acrescentou-se, então, uma situação-problema (problematizando - “E se der pane nesses meios?”), e os estudantes sugeriram o uso de cartas. Quando a professora lembrou que o correio também não estava funcionando, os estudantes concluíram que seria necessário viajar para se comunicar, e que isso era inviável (sistematizando). Após a discussão, bolsista e professora regente organizaram a turma, levaram-na até a praça em frente à escola (onde havia um "orelhão" - Figura 1), questionando os estudantes se sabiam onde estávamos indo, até sugerirem o "orelhão" - "porque ele é um meio de comunicação".

Figura 1 - Visita à praça em frente à escola

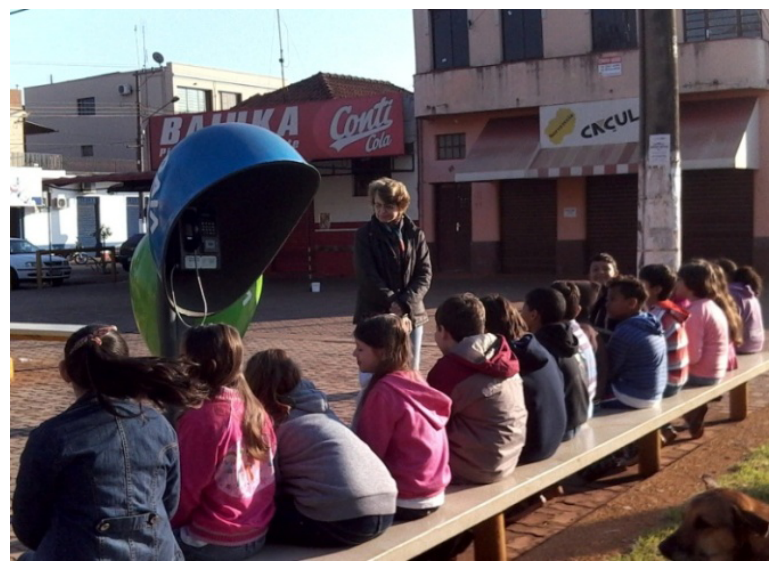

Fonte: As autoras. 
Lá, os alunos puderam manusear o aparelho e ler as instruções presentes nele; foi-lhes perguntado se já haviam usado um "orelhão" e em quais circunstâncias. Surgiram dúvidas, como o que eram as siglas $\mathrm{DDD}^{4}$ e $\mathrm{DDI}^{5}$ e uma operadora. A professora propôs que fizessem uma entrevista (sistematizando) com os pais sobre "Como eram os meios de comunicação antigamente", para incitar a curiosidade dos estudantes sobre os meios de comunicação "antigos". É oportuno ressaltar que a mudança de ambiente nos pareceu importante, pois, segundo Antunes, “[...] uma aula de verdade não se confina à sala de aula e os saberes na mesma provocados representam desafios para que os estudantes os contextualizem na vida que vivem, em muitos outros espaços onde convivem" (2013, p. 23).

$\mathrm{Na}$ semana seguinte a turma foi orientada a realizar uma pesquisa (sistematizando), que seria partilhada com os colegas. Após mais uma semana, os educandos foram dispostos em roda e iniciou-se uma discussão baseada nas pesquisas trazidas por eles (sistematizando), intituladas "De onde vieram a Internet e o computador?" Nesse momento foram discutidos aspectos históricos, como a guerra fria, os objetivos iniciais dessas invenções, como era seu funcionamento, tendo sido compartilhadas imagens sobre os primeiros computadores. Num dado ponto da discussão os estudantes passaram a questionar: "Como colocaram a Internet no computador?" Eles concluíram que, em suas pesquisas, não havia informações suficientes para responder à pergunta e, portanto, seria necessário investigar mais a respeito. De tal prática - pesquisa e discussão - desenrolaram-se outros questionamentos, como a origem da energia elétrica, que deu início a um projeto sobre a água, envolvendo investigações desde o ciclo da água à crise hídrica de São Paulo - que ocorria na época - o que nos mostra que um conhecimento evoca outros, conforme o estudante estabelece relações entre as informações adquiridas, dando-se assim a construção do conhecimento (ANTUNES, 2013).

\footnotetext{
${ }^{4}$ Discagem Direta a Cobrar.

5 Discagem Direta Internacional.
} 
Em seus Diários de Bordo os estudantes consideraram a prática como "[...] muito importante por que a gente precisa saber a história dessas coisas que tanto usamos e para a nossa aprendizagem é importante",; "Eu acho que essa atividade de ir pesquisar é bem mais legal do que a professora passar a atividade na lousa”; "[...] Eu gostei demais dessa atividade porque aprendemos coisas novas. Eu espero que continuamos assim aprendendo sempre mais. A aprendizagem não tem tamanho ela é infinita."

Após as experiências de pesquisa e discussão, foi sugerido aos estudantes a apresentação de seminários, de modo a organizar e difundir o conhecimento que vinha sendo construído ao longo do projeto. A princípio tinha-se em mente que a turma apresentasse para grupos menores, de $1^{\circ}, 2^{\circ}$ e $3^{\circ}$ anos, dentro da própria escola, com seminários e exibição de cartazes - essa ideia está em harmonia com o trazido por Freire, de que aprender é " [...] muito mais rico do que meramente repetir a lição dada. Aprender para nós é construir, reconstruir, constatar para mudar, o que não se faz sem abertura ao risco e à aventura do espírito" (p. 60, grifos do autor). As demais professoras da equipe escolar, no entanto, não permitiram as visitas em suas salas e, dessa forma, optou-se pela criação de um painel (Figuras 2 a 5). Os seminários foram feitos apenas entre os estudantes da turma participante da pesquisa, buscando manter o proposto na "Etapa 6" do projeto original.

Figuras 2 e 3 - Cartazes produzidos pelos alunos
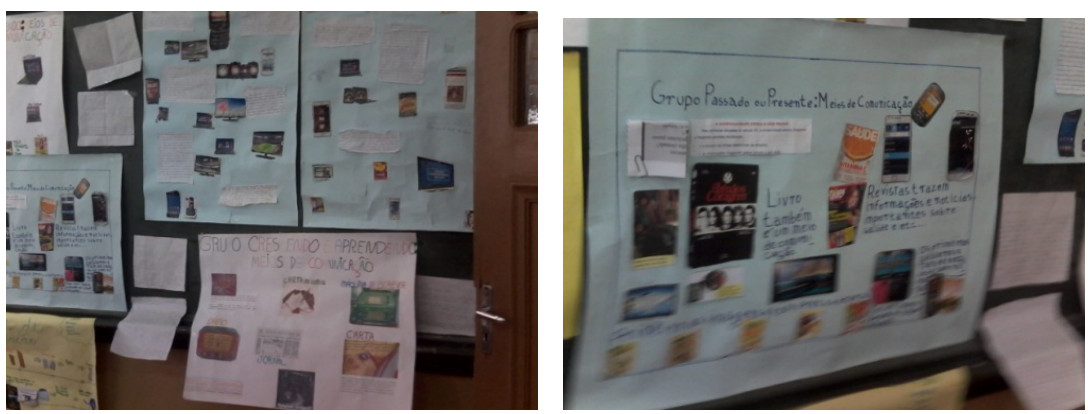

Fonte: As autoras.

${ }_{6}$ Não foram realizadas quaisquer correções de escrita ou pontuação nos escritos dos estudantes, destacados em itálico. 
Figuras 4 e 5 - Painel "Meios de Comunicação"
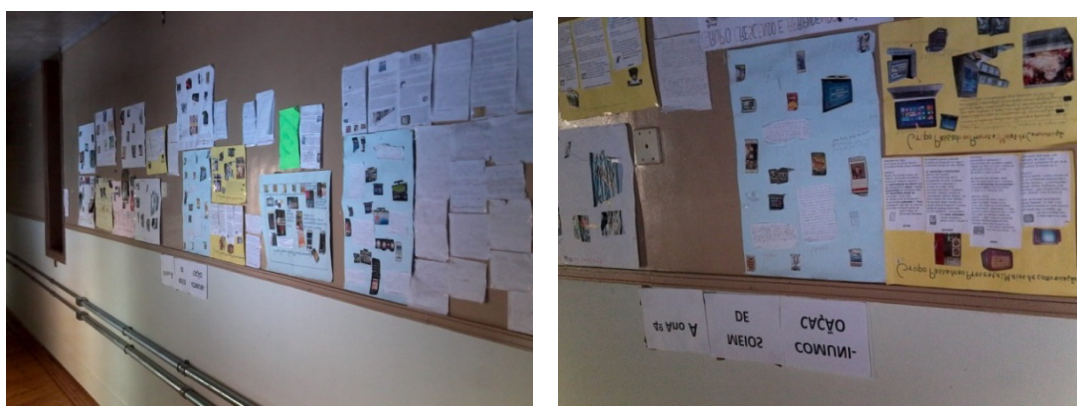

Fonte: As autoras.

Ainda dentro do "Projeto Meios de Comunicação" foi organizada uma excursão - prática solicitada pelos alunos na Roda de Conversa Inicial, no início do ano letivo - ao Laboratório do Centro de Línguas e à Biblioteca da Unesp Assis (Figuras 6 e 7), visando a proporcionar aos educandos algumas formas de se comunicar na atualidade. Essa ação pautou-se nas contribuições de Antunes, de que " $[. .$.$] aprender é um processo que se inicia a partir do confronto entre a$ realidade objetiva e os diferentes significados que cada pessoa constrói acerca dessa realidade, considerando as experiências individuais [...]" (2013, p. 32), que corroboram com o momento pedagógico "problematizando" de Oliveira, Almeida e Arnoni (2007).

Ambas as visitas foram monitoradas - ao Laboratório de Línguas, por estudantes do curso de Letras, e à Biblioteca, pelas funcionárias do espaço - e os estudantes puderam tirar dúvidas e conhecer o funcionamento dos dois ambientes, por meio de vídeos e das explicações dos monitores. Em seus registros os alunos descreveram todas as etapas da excursão, contudo o que aparentou chamar-lhes mais a atenção foi o fato de visitar a Universidade: "Gostei muito desta visita pois finalmente conheci a tal 'Faculdade,”; "Foi muito bom nós irmos à Unesp porque conhecemos a tal da faculdade que os adultos falam para nós entrarmos.” 
Figuras 6 e 7 - Visita ao Laboratório de Línguas e Piquenique
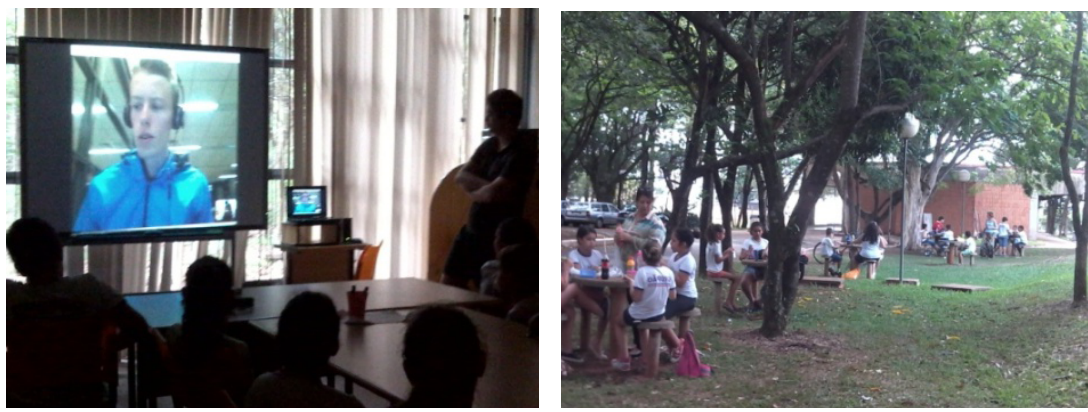

Fonte: As autoras.

Ao fim do Projeto foi solicitado aos estudantes que fizessem uma autoavaliação em seus Diários de Bordo. Entre os registros podemos destacar: "Eu gostei muito, foi uma experiência muito boa porque aprendi mais sobre os meios de comunicação"; "E acho que os cartases ficaram bom e que não precisa mudar nada. [...] E achei interessante porque, aprendi mais"; "Foi muito importante saber a evolução dos meios [de comunicação]"; "Eu gostei muito desses trabalhos e eu quero saber mais"; "Eu gostaria muito que as crianças que não aprenderam aprendesse junto [...]”; “Achei que a apresentação do meu grupo poderia ter pesquisado mais coisas e ter feito mais cartases".

Um registro interessante foi de um estudante que não participou da elaboração do seminário com seu grupo, o qual escreveu em seu Diário: “[...] eu deixei de aprender uma coisa que no ano que vem não seram repitidas".

No planejamento e execução do Projeto Meios de Comunicação, procuramos proporcionar aos estudantes o desenvolvimento da autonomia na busca de informações e o diálogo destas com o contexto sociocultural da atualidade. Mosé esclarece que é preciso estimular, nas crianças, o gosto por aprender, pois "[...] a vontade de conhecer é mais eficiente para o processo de aprendizagem do que a manutenção dos deveres cumpridos. Para isso, precisamos transformar as tarefas escolares, hoje repetitivas e desinteressantes, e vincular o aprendizado à ação [...]” (2013, p. 57). Nesse sentido, é preciso aproveitar a curiosidade das crianças, durante o processo de ensino-aprendizagem, despertando-lhes o 
interesse para o estudo. Incitar a curiosidade e a ação, por meio de pesquisas e vivências, traz aos estudantes uma dimensão mais palpável do conhecimento, construindo o diálogo entre as informações adquiridas e o saber dos educandos (ANTUNES, 2013).

\title{
Prática 3 - Boletim do Lixo: Enriquecimento da Sequência Didática "Produção e Destino do Lixo"
}

A sequência didática ${ }^{7}$ envolve leitura de textos jornalísticos e de divulgação científica, além de produção de resumos ou esquemas, visando ao desenvolvimento da autonomia e automonitoramento do estudante no processo de aprendizagem. Para isso é necessário que ele se aproprie de estratégias, procedimentos e outros conhecimentos sobre pesquisa, que incluem elaborar perguntas sobre o tema estudado, buscar informações, selecionar fontes adequadas, responder às perguntas de sua pesquisa, organizar informações, entre outros (SÃO PAULO, 2010). Para Oliveira, Almeida e Arnoni essa ação constitui-se no terceiro momento pedagógico da MMD - "sistematizando"

desenvolver situações de ensino que possibilitem ao aluno compreender as relações de sentido entre aspectos do seu saber imediato e elementos do saber mediato pretendido, por intermédio da explicitação dos aspectos da problematização e da discussão do saber científico a eles relacionado (2007, p. 154).

No Guia de Planejamento e Orientações Didáticas a escolha do tema "Produção e Destino do Lixo" é explicada da seguinte maneira:

\begin{abstract}
Nas duas últimas décadas vem crescendo a preocupação com a conservação do meio ambiente. [...] Colocar em discussão esse tema possibilita a educação da criança para a preservação do meio ambiente no sentido de favorecer o desenvolvimento de ações que estimulem o protagonismo infantil para que haja uma atuação de intervenção na comunidade escolar e, quiçá, em outras situações sociais mais amplas (SÃO PAULO, 2010, p. 132).
\end{abstract}

${ }^{7}$ Expressão utilizada para identificar o trabalho estruturado de forma sequencial, usando etapas ligadas entre si, procurando tornar mais eficiente o processo de ensino-aprendizagem. 
De acordo com Antunes, "[...] um saber somente importa ser ensinado quando instiga o aluno a uma associação ao mundo que vive, à realidade com a qual convive [...]" (2013, p. 33). Assim, buscamos proporcionar aos estudantes uma dimensão tangível sobre o tema trazido na sequência didática e, a princípio, pensamos em preparar um Boletim do Lixo da cidade, contendo informações sobre quanto lixo é produzido e quanto é reciclado, elaborado de acordo com a disponibilidade da escola.

O objetivo dessa prática foi possibilitar aos alunos a valorização de seu trabalho, além de dar-lhes a dimensão de que aquilo que produzem é útil e importante para a sociedade. Para a concretização da prática planejou-se visitar a Associação de Catadores de Materiais Recicláveis de Cândido Mota - Recicam (Figuras 8 e 9), permitindo aos educandos o contato com uma realidade objetiva, de modo a relacionar a teoria com a prática.

Durante o planejamento da prática a professora regente concluiu que não seria possível a elaboração do Boletim do Lixo, pois demandaria o auxílio de outros setores da escola (como funcionários da secretaria), e estes não poderiam prestar esse apoio. Sugeriu, contudo, que os estudantes poderiam entrevistar os trabalhadores da Recicam durante a excursão. Esta foi, portanto, a prática realizada e os estudantes foram orientados em sala a selecionarem perguntas para a entrevista, sem muita intervenção da professora regente ou da aluna bolsista.

Figuras 8 e 9 - Visita à Recicam
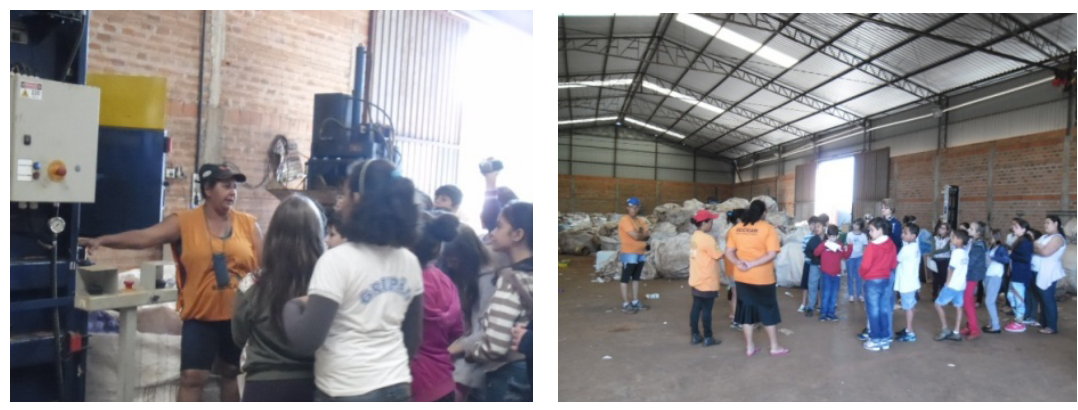

Fonte: As autoras. 
Durante a entrevista não houve igualmente qualquer intervenção da professora regente ou da bolsista e os estudantes ficaram livres para fazer perguntas às funcionárias - alguns utilizaram-se de roteiros, preparados previamente por eles, enquanto outros faziam perguntas de forma mais espontânea.

O grupo trouxe questões interessantes aos trabalhadores, como: "Qual a máquina em que vocês mais gostam de trabalhar?"; "Qual material reciclável é mais fácil de vocês mexerem e reciclarem?"; "Qual material reciclável dá pra vocês aproveitarem mais?". Ainda perguntaram se alguma das trabalhadoras havia encontrado algo valioso e se já haviam se ferido ou contraído algum tipo de doença. Após a entrevista as catadoras mostraram aos estudantes o funcionamento das máquinas usadas em seu trabalho e os ensinaram a separar os materiais recicláveis.

Ato contínuo, já na escola, foi realizado o registro da ação nos Diários de Bordo. Em sua maioria os estudantes efetuaram uma descrição da visita a campo, com destaque para o funcionamento das máquinas. Podemos ressaltar aqui alguns apontamentos: "Gostei pois aprendi a reciclar"; "Eu gostei quando a $L .{ }^{8}$ perguntou em que a reciclagem ajuda bastante, ela respondeu que ajuda no futuro das crianças e principalmente a natureza"; "Eu gostei muito porque lá conheci o trabalho de outras pessoas"; "Lá é muito legal eu voltaria, conserteza".

Em consonância com o Projeto Meios de Comunicação, visto que não foi possível elaborar o Boletim do Lixo, a professora sugeriu a produção de uma notícia, baseada na excursão ${ }^{9}$ (Figura 10) - a fim de trabalhar escrita e gêneros textuais - e tentar a publicação em um jornal da cidade. Os textos foram produzidos em conjunto pelos estudantes, com o auxílio da educadora, e publicados pelo jornal $O$ Diário do Vale, em 5 de novembro de 2014, em Cartas dos Leitores (Figura 11).

8 O nome da aluna foi ocultado para evitar a exposição da mesma.

9 Uma matéria sobre a visita dos alunos à Recicam foi publicada no jornal $O$ Diário do Vale, em 20 de setembro de 2014 . 
Figura 10 - Visita dos estudantes à Recicam publicada no Jornal O Diário do Vale, em 20 de setembro de 2014
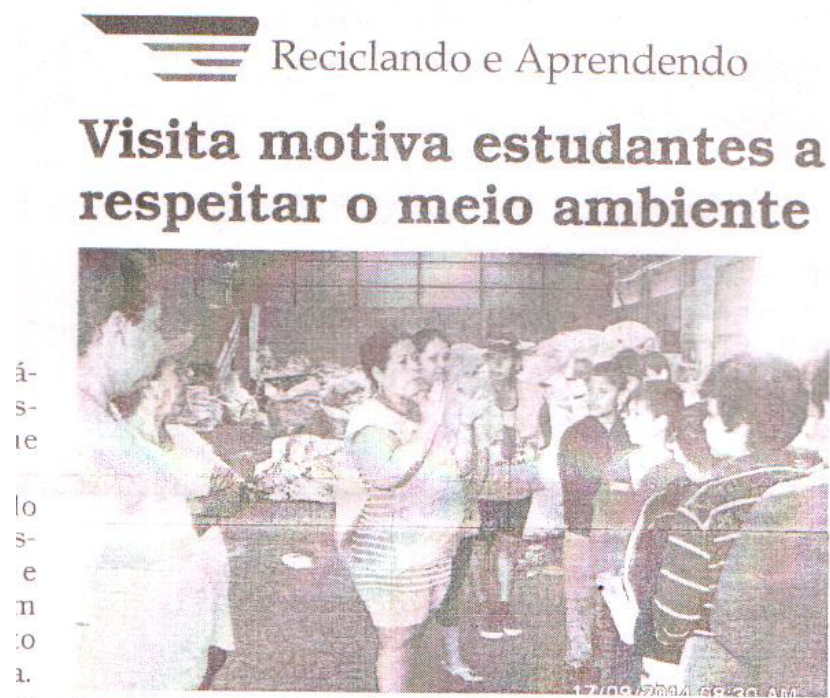

Cândido Mota - Os alunos do $4^{\circ}$ ano A da Escola Estadual Professora Clotilde de Castro Barreira, o Grupāo, fizeram na quarta-feira uma visita à Recicam, acompanhados da professora Lucimar Pimentel de Castro, onde aprenderam sobre reciclagem e preservação do meio ambiente. Foram bem recebidos pelas trabalhadoras da associação, que responderam às perguntas feitas por eles e, aproveitando a oportunidade, mostraram todo o processo de reciclagem e como funcionam as máquinas. "As crianças estão ensinando aos adultos a importância da reciclagem", explicam as trabalhadoras da Recicam. A reciclagem é importante para um mundo melhor, pois diminui a poluição ambiental e ajuda financeiramente mais de vinte mil familias de Cândido Mota. Os alunos agradecem a atenção e acolhida recebidos, bem como as informações que foram dadas pelas trabalhadoras.

Fonte: Jornal O Diário do Vale, em 20 de setembro de 2014. 
Figura 11 - Cartas dos Leitores publicadas no Jornal O Diário do Vale, em 5 de novembro de 2014

\section{Cartas dos Leitores Notícia interessante}

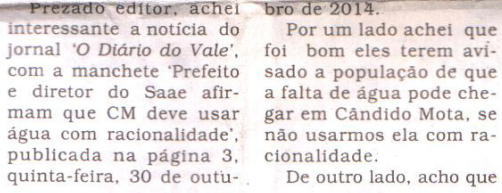

Por um lado achei que foi bom eles terem avisado a população de que a falta de água pode chegar em Cândido Mota, se não usarmos ela com racionalidade.

De outro lado, acho que

\section{bro de 2014 .}

se eles sabiam que a água nāo é infinita, deviam ter avisado antes para que não chegasse a esse ponto.

Acho também que todos deviam ter economizado a água desde o começo, pois deviamos ter pensado nas nossas próximas geraçōes e nosso futuro, pois a água não é infinita. Ela ê um dos maiores bens naturais para a vida.

Obrigada pela atenção.

* Ana Clara Clausen da Silva, aluna do $4^{\circ}$ ano A da escola 'Professora Clotilde de Castro Barreira'.

\section{Viver sem água é impossível}

Caro editor, no jornal $O$ Diário do Vale' li a publicaçáo 'Prefeito e diretor do Saae afirmam que $\mathrm{CM}$ deve usar água com racionalidade', que foi publicada na quinta-feira, 30 de outubro de 2014 , na página 3.
Gostaria que as autoridades tivessem tomado essa atitude antes de tudo 1s so acontecer. Agora acreditu yni a populaçăo está conseguindo enxergar a realidade: viver sem ảgua é impossivel!
Muito bom da parte da administração que está tomanclo providèncias para conscientizar as pessoas a economizar. A água tem que ser utilizada com inteligência, pois se continuar assim, nossos filhos e ne- tos não terão água no futuro, e nem mesmo saberemos se haverá um futuro.

Obrigada pela atenção.

* Gabriela O.B. Coutinho, aluna do $4^{\circ}$ ano A da escola 'Professora Clotilde de Castro Barreira'.

\section{Usar água com racionalidade}

Caro senhor editor, eu li a notícia no jornal 'O Diário do Vale', página 3 . quinta-feira, sobre 'Prefeito e diretor do SAAE afirmam que $\mathrm{CM}$ deve usar água com racionalidade', e concordo que CM deve usar água com racionalidade, mas eu também dis- cordo, porque passaramse vários prefeitos e só agora foram perceber isto! A populaçāo está na mão da administraçăo, $e$ se a água acabar, todos nós morreremos.

As pessoas não aguentam ficar trẽs dias sem beber água. Nós poderiamos ter começado antes a economizar água. Todos sabiam que algum dia a água ia acabar, mas ninguém li gou para isso.

Então agora estão chegando as consequencias e por nẫo ter tido a responsabilidade com um bem tão precioso.
Eu acho que devemos ter mais responsabilidade, porque agora não dá mais pra voltar atrás.

Obrigada pela sua atenção.

* Carla Damasceno de Araújo, aluna do $4^{\circ}$ ano A da escola 'Professora Clotilde de Castro Barreira'.

Mosé (2013) enfatiza que “[...] a aprendizagem deve ser importante no presente pelo seu valor de uso [...]", verificando-se, nesse aspecto, a importância do seu diálogo com o contexto social, cultural e econômico nos quais se insere. Antunes (2013, p. 60) destaca a relevância em se valorizar o

[...] protagonismo dos alunos como produtores de um saber pessoal, acrescentando a importância de o educador [...] aceitar como certeza pedagógica indiscutível que aquilo que ensina aos alunos não são volumes de informações que recebem, mas o que eles mesmos realizam, fazendo uso próprio dessas informações 
O que pudemos observar durante a realização da entrevista, totalmente conduzida pelos estudantes. Buscou-se, assim, trazer o conteúdo dos livros didáticos para a "realidade", para o dia a dia dos estudantes, e levá-los a refletir sobre os problemas da atualidade e sobre as possíveis formas de lidar com eles.

\section{Prática 4: Roda de Conversa}

Ao final do ano letivo foi realizada uma nova Roda de Conversa com os estudantes, com duração aproximada de 1 h30min, a fim de ouvirmos seus apontamentos acerca das ações executadas durante o ano letivo e identificar possíveis rupturas epistemológicas realizadas por eles. Essa atividade foi organizada objetivando articulação, em termos lógicos do todo e parte, ou seja, da unidade do conceito à diversidade dos contextos.

Quando questionados sobre o ano letivo de 2014, e se haviam notado mudanças com relação aos anos anteriores, eles o avaliaram como "legal", porque "a gente fez várias atividades diferentes, a gente passeou bastante", e que foi um ano "melhor que os outros". "Eu gostei porque eu não sabia fazer grupo pra fazer cartaz e esse ano eu aprendi".

Perguntados se tinham gostado de fazer esses trabalhos, responderam "Sim, muito!", pois não trabalhavam em grupo antes e "quando fazia, fazia errado". Disseram ainda que as mudanças "ajudaram muito" em sua aprendizagem, de forma que nenhum deles considerou que as mudanças não os havia ajudado.

Sobre mudarem mais alguma coisa, afirmaram: "Acho que já mudou tudo o que tinha que mudar" e sugeriram "ter mais pesquisas" е "eи acho que pro ano que vem a gente poderia, vamos supor, estudar mais geografia, ciências...”.

Entre as práticas de que mais gostaram destacaram as saídas a campo, mas também o Diário de Bordo (Figura 12): "você pode ler lá no diário de bordo o que você fez, e você relembrar as coisas"; "acho que o diário de bordo ajudou a gente, porque a gente vai passar o que está sentindo"; "eu gostei do diário de bordo porque qualquer passeio que a gente faz, a gente escreve. Daí, se a gente esquecer alguma informação, a gente pode ir lá e ver pra lembrar". Também concluíram que a escola tinha ficado mais interessante após as práticas, pois "ficou muito mais animada". 
Figura 12 - Registro/Diário de Bordo

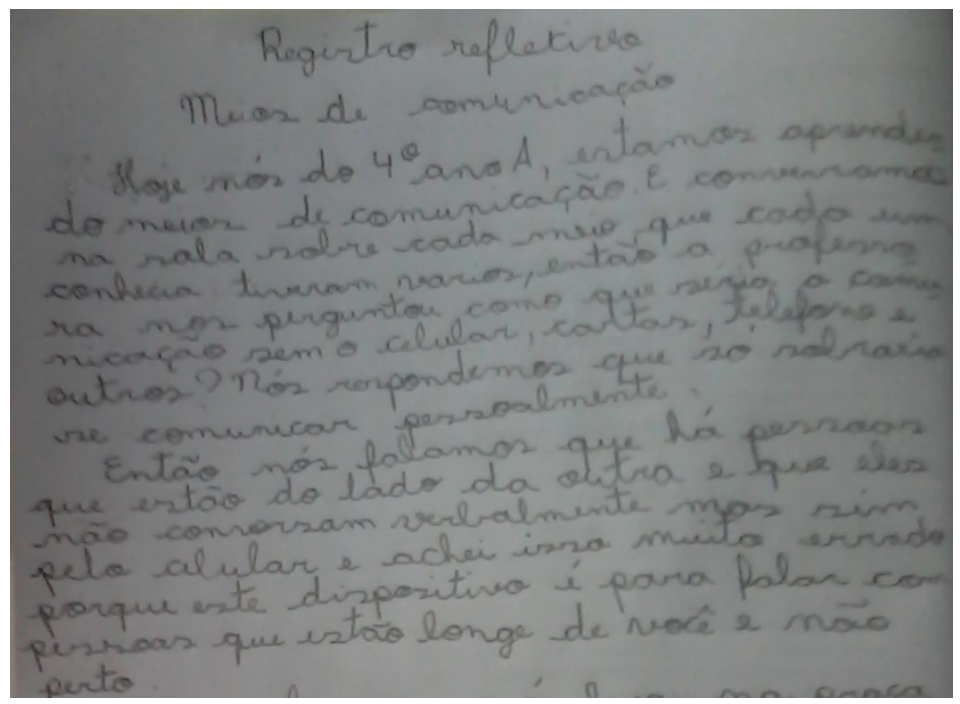

Fonte: As autoras.

Perguntamos aos estudantes se acharam ter tido mais espaço para expor suas ideias, ao que responderam afirmativamente. Quanto a esse "espaço", eles o classificaram como "grande". Segundo um dos alunos, "no primeiro dia que a gente fez a roda de conversa, nós não falamos muito porque a gente estava com vergonha. Mas agora que a gente já conhece, já faz um tempão, agora a gente pode expor nossas ideias". Os estudantes explicaram que essa vergonha era tanto pela presença de uma pessoa diferente em sala - no caso, a aluna bolsista - quanto por não terem "feito isso antes".

Quando questionados se esse espaço era suficiente, alguns afirmaram que "esse espaço ta bom", enquanto outros acreditam precisar de mais espaço, "porque as nossas ideias nunca acabam". A turma foi, então, questionada se era importante que a professora ouvisse suas ideias na preparação das atividades, ao que responderam: "se a gente trabalha assim na sala, todo mundo junto, eu acho assim que aplica a nossa aprendizagem"; "eu acho importante a professora ouvir nossas ideias porque com nossas ideias ela pode tornar as atividades, a aula, mais moderna, e diferente das outras". 
A respeito do que achavam ser uma escola boa, responderam: "é quando tem cultura pros alunos e não tem briga, não tem violência, não tem bullying, não tem... é uma escola em comunidade"; "uma escola boa é quando os alunos respeitam os professores, e algumas professoras - não é todas - algumas professoras se... tem que ter responsabilidade. Se pegou a classe, tem que ficar. Mesmo se for substituta ou permanente, tem que ficar, porque é responsabilidade"; "pra mim uma escola boa tem que ter um bom aprendizado"; "uma escola que se passasse de ano, mas aprendendo, não só por passar"; "eu concordo que as professoras não podem sair da sala, porque até prejudica os alunos, que os alunos acabam ficando nervosos e acabam até formando briga!". Quanto a uma escola "não tão boa", indicaram: "uma escola onde os professores ensinam a matéria, mas os alunos não querem aprender essa matéria"; "quando a professora não ensina direito"; "que tivesse preconceito, bullying, brigas e desrespeito com todos da escola, inclusive os mais velhos e inclusive os colegas"; "onde os professores não quisessem dar ouvido aos alunos"; "numa escola ruim, os amigos não iam querer ser amigos um do outro, eles iam brigar muito".

Perguntamos o que seria uma "boa professora" e o que seria uma professora "não tão boa", recebendo como resposta: "uma professora boa é quem ensina bastante as coisas, e uma ruim é quem fica gritando com os alunos"; "é aquela que ensina e espera o outro terminar, a ruim já vai passando tudo na hora"; "uma professora boa é a que aceita ser corrigida pelos alunos, e uma ruim fala que os alunos não sabem, e só ela que sabe"; "uma professora ruim é a que dá a resposta"; "a professora boa é quem ensina o aluno a cada vez ser melhor"; "a professora boa é aquela que ensina, tem paciência e escuta a opinião dos alunos, uma professora ruim é o contrário da professora boa"; "uma professora de qualidade ruim, ela não ouviria os alunos"; "eu acho que assim, uma professora tem que ser ao mesmo tempo exigente, e ao mesmo tempo tem que ser divertida. Eu acho também que uma professora boa tem que escutar a opinião dos alunos, escutar maneiras diferentes de fazer a lição"; "a professora ruim, ela não faz nada, não passa lição, fica só sentada o dia inteiro!"

Para Kinney e Wharton (2009, p. 21), “o compromisso de escutar as crianças e consultá-las é fundamental para se pensar, desenvolver e praticar o currículo". Antunes (2013) acrescenta ser necessário ao educador conhecer quem é seu aluno, seu anseio, os saberes prévios que carrega, consequência de 
suas experiências vividas. Por meio de tais contribuições elaboramos a Roda de Conversa como uma maneira de avaliar e refletir a prática pedagógica de forma colaborativa, unindo pesquisadoras, professora e alunado em prol do mesmo objetivo: uma relação ensino-aprendizagem significativa para os educandos. Embora já tivéssemos os Diários de Bordo, consideramos que seria importante que os estudantes pudessem se expressar também oralmente, em conjunto, para que "suas vozes, suas opiniões e seus entendimentos sejam ouvidos e tornados mais visíveis" (KINNEY; WHARTON, 2009, p. 21).

\section{Reflexões-Síntese}

Ao longo desta pesquisa foi possível perceber a importância do trabalho colaborativo, considerando os estudantes como sujeitos ativos durante o processo de ensino-aprendizagem. Os momentos de troca e as rodas de conversa mostraram-se fecundos, propiciando experiências positivas, na efetivação das ações. Os apontamentos trazidos pelos alunos nos proporcionaram o norteamento necessário para a elaboração de práticas condizentes com suas necessidades e com seu "mundo cultural", como sugere Antunes (2013), demonstrando a imprescindibilidade da escuta no ambiente escolar.

Buscamos, de certa maneira, materializar e revelar a efetividade das colaborações de autores como Antunes (2013), Kinney e Wharton (2009) e Mosé (2013), de que, se o educador, no início do ano letivo, propuser atividades de escuta e discussão de ideias a seus estudantes, terá recursos e subsídios para enriquecer o material pedagógico adotado por ele ou pela escola. Tal ação pode parecer simples e evidente, todavia infelizmente não é corriqueira no contexto escolar. Em acréscimo, mostrar que isso funciona e não requer recursos financeiros, mas uma mudança do papel do professor, é a principal contribuição deste trabalho.

A escuta dos alunos permite que o professor torne suas aulas mais atraentes e contextualizadas para eles. Santos (2011) argumente que a falta de concentração, o desinteresse e a indisciplina na sala de aula podem ser suprimidos por meio de um ensino atraente, capaz de proporcionar uma aprendizagem 
significativa pela via do prazer - do "gostar de aprender" sugerido por Mosé (2013) - tornando possível a construção de um ambiente diferenciado em sala de aula, mediante práticas pedagógicas dinamizadoras.

Observamos, ainda, a relevância da motivação do professor para catalisar os recursos materiais e humanos existentes na escola, bem como na comunidade em que a escola está alocada, objetivando alcançar uma metodologia pedagógica mais dinâmica e significativa para seus alunos (GUENTHER, 2012).

Cabe ressaltar que a escuta inicial tomou menos de um dia de aula da turma, contudo propiciou os subsídios necessários para a elaboração de ações para todo o ano letivo, que tivessem sentido e significado aos estudantes, facilitando o diálogo, preconizado por Antunes (2013), entre a "realidade objetiva" e o que se aprende na escola. Bastam ao educador algumas perguntas sobre os gostos, pensamentos e apontamentos de seus educandos com relação à escola, ao material didático, às atividades escolares e ao próprio dia a dia escolar, e tem-se muito com o que trabalhar.

Por fim ressalta-se, ainda, a importância de propostas como esta, da elaboração conjunta de atividades e práticas diferenciadas e de permitir a todos os envolvidos uma participação ativa no processo de ensino-aprendizagem - visto que os estudantes podem trazer contribuições significativas para a construção de práticas diferenciadas em sala de aula. Tais ações puderam oportunizar aos estudantes experiências e vivências além do conteúdo didático, embora pensadas a partir deste, colaborando, assim, não só com a formação "acadêmica" dos estudantes, mas também para a vida, como cidadãos capazes de refletir, questionar e construir, de fato, o conhecimento. $\mathrm{O}$ momento final do projeto, a segunda Roda de Conversa, deixa evidente a existência de rupturas epistemológicas por parte dos estudantes, com destaque para o fato de eles declararem terem aprendido a trabalhar em grupo, desejarem para o próximo ano realizar mais pesquisas, ampliar as pesquisas para áreas como Geografia e Ciências, terem dado um sentido positivo ao Diário de Bordo, passarem a considerar a escola mais interessante por ter ficado "mais animada", poderem expor suas ideias e perceberem que estas podem fazer parte das atividades da sala de aula. Tais aspectos constituem-se agora em um novo ponto de partida, segundo a Metodologia da Mediação Dialética, aqui empregada de forma adaptada (OLIVEIRA; ALMEIDA; ARNONI, 2007). 


\section{Referências}

ANTUNES, C. Professores e professauros: reflexões sobre a aula e as práticas pedagógicas diversas. 7. ed. Petrópolis, Rio de Janeiro: Vozes, 2013.

FREIRE, P. Pedagogia da autonomia: saberes necessários à prática educativa. 50. ed. Rio de Janeiro: Paz e Terra, 2015.

GUENTHER, Z. C. Crianças dotadas e talentosas... não as deixem esperar mais! Rio de Janeiro: LTC, 2012.

HELM, J. H. Os desafios contemporâneos na educação infantil. In: HELM, J. H.; BENEKE, S. (Org.). O poder dos projetos: novas estratégias e soluções para a educação infantil. Tradução Vinícius Figueira. Porto Alegre: Artmed, 2005.

KINNEY, L.; WHARTON, P. Tornando visível a aprendizagem das crianças: educação infantil em Reggio Emilia. Tradução Magda França Lopes. Porto Alegre: Artmed, 2009.

MATTEI, G. O professor e aluno com altas habilidades e superdotação: relações de saber e poder que permeiam o ensino. Revista Educação Especial, 21(31), p. 75-84, 2008.

MENDES, E. G.; VILARONGA, C. A. R.; ZERBATO, A. P. Ensino colaborativo como apoio à inclusão escolar: unindo esforços entre educação comum e especial. São Carlos: EdUFScar, 2014.

MOSÉ, V. A escola e os desafios contemporâneos. Rio de Janeiro: Civilização Brasileira, 2013.

OLIVEIRA, E. M.; ALMEIDA, J. L. V.; ARNONI, M. E. B. Mediação dialética na educação escolar: teoria e prática. São Paulo: Edições Loyola, 2007.

SANTOS, S. M. P. dos. O brincar na escola: metodologia lúdico-vivencial, coletânea de jogos, brinquedos e dinâmicas. 2. ed. Petrópolis, RJ: Vozes, 2011.

SÃO PAULO (Estado). Secretaria da Educação. Ler e escrever: guia de planejamento e orientações didáticas; professor - $3^{\mathrm{a}}$ série. Secretaria da Educação, Fundação para o Desenvolvimento da Educação; adaptação do material original, Marisa Garcia, Milou Sequerra. 2. ed. São Paulo: FDE, 2010.

THIOLLENT, M. Metodologia da pesquisa-ação. 16. ed. São Paulo: Cortez, 2008.

Recebido em: 12/11/2016

Aceito em: 17/2/2017 